\title{
Chinese students' social integration into the university community: hearing the students' voices
}

\author{
Helen Spencer-Oatey ${ }^{1}$ (D) Daniel Dauber ${ }^{1} \cdot$ Jing Jing $^{1} \cdot$ \\ Wang Lifei ${ }^{2}$
}

Published online: 22 November 2016

(C) The Author(s) 2016. This article is published with open access at Springerlink.com

\begin{abstract}
According to UNESCO statistics, the People's Republic of China (PRC) sends far more students to study overseas than any other country in the world. Similarly, from the receiving countries' point of view, PRC students form by far the highest proportion of international students. In many respects, this is a success story, but it also poses a number of risks to universities. This paper focuses on one of those key risks that of student dissatisfaction (including from PRC students themselves). Using a sequential mixed-method study, it addresses two research questions: (a) Chinese students' level of satisfaction with their social integration into the university community and (b) the barriers that Chinese students' perceive in becoming more socially integrated into the university student community. The research finds that many Chinese students are dissatisfied with their range of friendships and that they find it more challenging to socialise with students of other nationalities than other students do. They point out a number of barriers to integration, with cultural distance playing a major role, but also argue for the impact of individual factors. The paper concludes by considering the implications for universities and suggestions for further research.
\end{abstract}

Keywords Integration - Chinese students · Social mixing - Cultural distance · Motivation · Language proficiency

Helen Spencer-Oatey

helen.spencer-oatey@warwick.ac.uk

Daniel Dauber

d.dauber@warwick.ac.uk

Jing Jing

jessicajing1027@hotmail.com

Wang Lifei

philipw@126.com

1 Applied Linguistics, University of Warwick, Coventry CV4 7AL, UK

2 University of International Business and Economics, Beijing, China 


\section{Introduction}

According to UNESCO (2016, p. 12), the People's Republic of China (PRC) has the largest number of students studying overseas of any country in the world, with the current figure reaching around 680,000 and with the top 5 receiving countries being the USA (ca. 225,000), Japan (ca. 90,000), Australia (ca. 88,000), UK (ca. 82,000) and the Republic of Korea (ca. 38,000). From the receiving countries' perspective, PRC students form by far the highest proportion of international students, comprising over double the number of the second largest group in the USA, over 5 times the number in Japan and Australia, over 3.5 times the number in the UK and over 15 times the number in the Republic of Korea.

In many respects, these figures are a success story for the receiving countries, since international recruitment is of critical importance to universities worldwide, often primarily for financial reasons but also for broader internationalisation reasons. Yet, universities are also aware of the dangers. Their concerns are wide ranging and include financial risk if the Chinese market fails, academic risk if the numbers affect academic attainment and student satisfaction risk if students dislike the diversity range. An article in the Wall Street Journal (Belkin and Jordan 2016) with the headline "Heavy recruitment of Chinese students sows discord on US campuses" illustrates the challenges of handling the situation. The article attracted 676 comments, with criticisms and counter-criticisms of American university recruitment policies and of Chinese and American students' attitudes and behaviour.

In terms of internationalisation, there is sometimes an assumption that simply attracting large numbers of international students is the key. Clearly, it is an important element, but it is more a valuable prerequisite than an end in itself, as a recent British Council (2014) report explains,

"simply having a diverse student body does not mean the education or even the campus is global in nature. What comes as an essential part of a global education is the inclusion of international students in communities and classes. Integration of all students is an elemental factor in the expanding concept of internationalisation.” (p. 4)

They emphasise the importance of integration, and this is the focus of our article. There have been various interpretations of the concept (e.g. see Boski 2008), but following Spencer-Oatey, Dauber and Williams (2014, p. 9), we interpret it as a process of "intermixing; personal adaptation; synthesising, mutual adjustment and change; and a sense of belonging". We focus on the issue of intermixing, with particular reference to PRC students. Our selection of PRC students is not because we assume them to be different from other international students, but rather because they now form such a large proportion of the university student population in higher education (HE) institutions around the world. This means that universities need to be able to understand better how this dominance may (or may not) affect all students' experiences of university life.

\section{Literature review}

More than 10 years ago, a UKCOSA (2004) study found that only $15 \%$ of Chinese students reported having any UK friends. The report commented that "It is a major concern that two of the largest national groups on campus (Greek and Chinese students) mainly socialise with fellow nationals or other international students on campus". Classic research by psychologists into cross-cultural adaptation provides insights into why such lack of integration amongst international and home students should be a concern to university managers. 
Furnham and Bochner (1982), in pioneering work in this area, explored the amount of difficulty students studying at UK English language schools experienced in dealing with everyday social situations. They found that those students who were from culturally distant cultures (the Middle East and Far East) reported greater difficulty than those from northern Europe. Similarly, Ward and Kennedy (1993a, 1993b) found that cultural similarity-dissimilarity affected the sociocultural adaptation of both secondary school students and of university students, as well as host-guest relations. A greater amount of interaction with local students and staff was associated with fewer social difficulties, improved communicative competence and better overall adaptation to life overseas. Of course, host-guest interaction is a two-way process. As Kim (2001) and Berry (2006) point out that it is not only sojourners who need to be willing to engage with hosts; the receptivity of the host environment and of individuals in particular are also crucially important.

This psychological research indicates that integration amongst the diverse student body is particularly helpful for adaptation, especially sociocultural adaptation - the adjustments needed to function effectively in an unfamiliar setting. However, this adaptation is not just beneficial for social or psychological welfare reasons. As Glass and Westmont (2014) recently reported, academic success for both home and international students is associated with a high sense of belonging to one's university and high levels of intercultural interaction. The implications are summarised in a recent British Council (2014, p. 4) report,

Integration of all students is an elemental factor in the expanding concept of internationalisation not only due to immediate student outcomes of comprehensive learning and cultural awareness but also due to long term benefits for the individual, the institution and the UK. Risks of separation to international students include at best, feelings of isolation that manifest in poor social and academic performance and at the very worst, risks to their personal safety. The positive effects and outputs of productive integration of international students not only affect the students and faculty, but the calibre of education itself and the long-term promotion and marketing prospects of a university and a nation.

So what is the situation amongst Chinese students? Rather strangely, there has been surprisingly little research, especially recently, in relation specifically to the social integration of Chinese students. Much of the research into Chinese students studying abroad has focused on their academic life, with particular attention paid to their levels of participation in class (e.g. Hodkinson and Proropat 2014; Liu 2002), their styles of learning (e.g. Jin and Cortazzi 2006, 2011) and more recently their levels of academic attainment in comparison with their peers (e.g. Crawford and Wang 2015). There has been much less research on Chinese students' social interaction with people from different backgrounds.

A few studies have explored the issue in relation to international students in general. For example, Sovic (2009) interviewed a total of 162 first-year students from Japan, South Korea, Hong Kong, Taiwan, India, the USA and the UK, studying at a university in London, on their experiences at the university, especially socially. She reports that although it is often stated that Asians "stick together", international students actually perceived home students as sticking together, as well as vice versa. The reasons given for lack of integration were different backgrounds and schooling, shyness, language and openness/interest. A similar but somewhat expanded set of reasons were reported by Peacock and Harrison (2009) through interviews with UK students. In terms of patterns of interaction, they list the following impacting factors: language, introversion, different interactional norms/patterns (e.g. turn- 
taking in group work), different social habits (e.g. drinking alcohol), lack of shared cultural reference points and fears of peer disapproval. Two notable elements they report are UK students' fear of being "swamped" by international students, and their explicit stereotyping of international students, particularly those assumed to be Chinese.

With regard to research on social interaction in relation specifically to Chinese students, there is surprisingly little. Most studies are either of international students as an undifferentiated group or else they focus on Chinese as (language) learners (e.g. Jin and Cortazzi 2006, 2011). Two exceptions are Spencer-Oatey and Xiong (2006) and Chen and Ross (2015). The former, in a study of PRC students' sociocultural adaptation at a UK university, found that the Chinese students reported greater difficulty with social interaction than with adjusting to academic life. In the latter, Chen and Ross (2015) conducted in-depth semi-structured interviews with 24 Chinese undergraduate students at a Midwest university in the USA and report that there is a strong "Chinese educational enclave". They maintain that the Chinese community is complex, creating both possibilities and challenges, and they recommend that more research is carried out into its intricacies, so that important perspectives are not overlooked.

Given, therefore, the large number of Chinese students studying in many different countries of the world, combined with the limited amount of research that goes beyond an educational learning focus to explore issues of social integration for Chinese students, further research is particularly needed in this area. We therefore sought to address the following questions in a sequential mixed-method study.

RQ1: How satisfied are Chinese students with their social integration into the university community?

RQ2: What barriers do Chinese students themselves perceive in becoming more socially integrated into the university community?

The first question explores the extent to which Chinese students desire greater social integration, since motivation is likely to be a key element in achieving this. However, even if they are highly motivated, this does not necessarily mean that they will successfully achieve it. A number of factors may hamper them, and the second question explores what Chinese students perceive those barriers to be.

\section{Method}

We decided to use a sequential mixed-method study to explore the research questions. In terms of design, we used a follow-up qualitative extension to a core quantitative study (Morgan 2014).

\section{Core quantitative study}

Working in collaboration with the International Office at a British Higher Education Institution (henceforth BHEI) that is a member of the Russell Group, ${ }^{1}$ we added a number of questions

\footnotetext{
${ }^{1}$ The Russell Group is a self-selected group of 24 leading UK universities which are committed to maintaining the very best research, an outstanding teaching and learning experience and unrivalled links with business and the public sector.
} 
relevant to internationalisation to two surveys run by the external organisation, i-Graduate, Student Barometer (SB) for home students and International Student Barometer (ISB) for international students. ${ }^{2}$ There were six Likert-type items - two on friendship with people from other countries, two on working in groups with people from other countries and two on intercultural skills. Following each pair of items, respondents were given the opportunity to add open comments if they wished. In this paper, we focus on students' responses to questions on friendships (i.e. social integration) that were collected in the summer of 2014.

A total of 2031 undergraduate (UG) and postgraduate taught (PGT) students completed the surveys at the BHEI in the summer of 2014. Table 1 shows the distribution of respondents according to region/country (UK, EEA, China and other overseas). We also compared the relative distribution in our sample to the distribution in the entire population, ${ }^{3}$ i.e. the entire BHEI. As can be seen, the relative distribution in the sample and in the BHEI population is almost identical. Thus, our sample, with respect to the chosen regional clusters, is representative for the population, and no bias was introduced by creating these categories ex-post.

We decided to separate international students in this way for the following reasons: European students are treated in the UK as "home" students for fees purposes, but according to our personal teaching experience, they often have different integration experiences from many other non-UK students (Spencer-Oatey and Dauber 2016). So, we were interested in exploring how similar or different their perceptions were compared with other non-UK students as well as with UK students. We decided to use the EEA as an entity, rather than the more political unit of the European Union, since it did not seem to make sense to exclude countries like Switzerland and Norway. This group did not include the UK, since a separate cluster was created for these students. Secondly, Chinese students constitute approximately $20 \%$ of all non-UK students at the BHEI and they were the nationality singled out for comment most frequently in the survey as a whole, as well as with reference to group work. For these reasons, we decided to treat China as a separate national cluster.

The quantitative data was imported into $\mathrm{R}$, and a range of statistical analyses was carried out. Since the Likert scales in the SB and ISB surveys are all four-point, we used non-parametric tests since such a short scale reflects rather ordinal data. As there were noticeably more Chinese respondents at PGT level than UG level, we carried out separate analyses at PGT level as well as with the whole sample. The open comments, along with demographic data, were imported into the qualitative data analysis software programme, MaxQDA. There was a total of 429 open comments, all of which were brief and the full comment was thus chosen as the unit of analysis. They were all read and analysed a number of times, and then for the purposes of this study, we focused on those referring to Chinese students. For this, automatic lexical coding of all comments on students' nationality or country of origin (using all variants for a particular country) was carried out, and all instances were checked manually for accuracy of reference. Chinese students were commented on 28 times, and this compared with 54 comments on British students, 4 on Malaysian and 3 on Indian. All other nationalities were mentioned only once. Following this, a conventional content analysis (Hsieh and Shannon 2005) was carried out on the open comments.

\footnotetext{
${ }^{2}$ For more details, see http://www.i-graduate.org/universities/

${ }^{3}$ Data was retrieved directly from the student records of the analysed BHEI.
} 
Table 1 Distribution of sample, according to region/country, compared with the total BHEI student population

\begin{tabular}{|c|c|c|c|c|c|c|c|c|}
\hline & \multirow{2}{*}{$\begin{array}{l}\text { BHEI } \\
\text { student } \\
\text { population }\end{array}$} & \multirow{2}{*}{$\begin{array}{l}\text { Percent of BHEI } \\
\text { student population }\end{array}$} & \multicolumn{3}{|c|}{ Sample } & \multicolumn{3}{|c|}{ Percent of sample } \\
\hline & & & UG & PGT & Total & $\begin{array}{l}\text { UG percent } \\
\text { of sample }\end{array}$ & $\begin{array}{l}\text { PGT } \\
\text { percent of } \\
\text { sample }\end{array}$ & $\begin{array}{l}\text { Total } \\
\text { percent of } \\
\text { sample }\end{array}$ \\
\hline UK & 11,657 & $58 \%$ & 1,005 & 138 & 1,143 & $67 \%$ & $26 \%$ & $56 \%$ \\
\hline $\begin{array}{l}\text { EEA } \\
\text { (exclud- } \\
\text { ing UK) }\end{array}$ & 2,075 & $10 \%$ & 200 & 80 & 280 & $13 \%$ & $15 \%$ & $14 \%$ \\
\hline China & 1,727 & $9 \%$ & 43 & 122 & 165 & $3 \%$ & $23 \%$ & $8 \%$ \\
\hline $\begin{array}{l}\text { Other } \\
\text { overseas }\end{array}$ & 4,638 & $23 \%$ & 257 & 186 & 442 & $17 \%$ & $36 \%$ & $22 \%$ \\
\hline Total & 20,097 & $100 \%$ & 1,505 & 526 & 2,031 & $100 \%$ & $100 \%$ & $100 \%$ \\
\hline
\end{tabular}

\section{Extension qualitative study}

In the follow-up qualitative study, the third author interviewed 25 PRC students to gain more indepth insights into their viewpoints on social integration. We decided to focus on postgraduate students since there were substantially more PGT students from China in the sample than UG students (see Table 1). Both convenience and snowball sampling methods were used to select the participants; first, 7 students known personally to the third author were invited to participate, then another 11 were invited by other friends, whilst the rest of the participants ( 7 students) were introduced by the existing interviewees. In this way, the interviewer was not a stranger conducting research "on them" but rather a friend, or at least a friend's friend, who was interested in their opinions. Our aim was to enhance trust in this way so that they would be more open in talking about their experiences since the purpose of this second study touched upon sensitive topics. Interviews were conducted with 21 master students and $4 \mathrm{PhD}$ students from 7 faculties, studying 17 different subjects, such as Accounting and Finance, Business and Management, Creative Media Enterprises, Economics, Engineering, Mathematics and Sociology. In this sample, 14 students were female and 11 were male. Their length of time in the UK ranged from 1 to 7 years, with an average length of 2.76 years. Ethical approval for the research was obtained in accordance with the BHEI's guidelines.

Interviewees were contacted in advance to arrange mutually convenient times for the interviews. Interviews usually took place in quiet, undisturbed locations with good acoustics, including seminar rooms and quiet study rooms that were booked in advance. As suggested by Denscombe (2007), the seating was arranged before the interviewees arrived, such that the two parties were placed "at a 90 degree angle to each other $[\ldots]$ to allow for eye contact without the confrontational feeling" (p. 190) or at least in similar ways if this turned out to be impossible.

Given the respondents' varying degrees of fluency in English, all the interviews were conducted in Chinese (Mandarin) in order to remove any language barriers on the one hand and to enhance the accuracy and authenticity of the interview data on the other. This also helped to reduce the interviewer effect, as interviewees tend to be more open with interviewers of their own race and language than they are with those from different backgrounds (Davis et al. 2010).

The interviews were semi-structured in nature. There were no predecided questions, but rather a list of topics that covered the issues and themes identified in study 1. Each interview 
started with a broad question such as asking about the interviewee's life in the UK and then moved to their friendship patterns. When an interviewee mentioned integration related issues, they were invited to talk more fully about their experiences in relation to this. They were allowed to talk freely and were not pushed in any direction, thereby giving them the opportunity to develop their ideas and speak extensively about the topic (Denscombe 2007). Specific issues were only raised if an interviewee did not take the initiative to talk about it; for instance, if the interviewee did not mention anything about student numbers, they were asked a question such as the following: "What is the mix of nationalities in your accommodation or on your course?" At all times, the questioning remained as neutral and objective as possible. When needed, issues were probed by showing interest in what had been said and asking for further information; confirmation checks were also used at times to make sure there were no misunderstandings. Attempts were made to find out how the interviewees interacted with the three different groups, namely, PRC, UK and other international students. However, they tended to use the word foreigners to refer to all people who were not ethnically Chinese.

The length of the interviews varied from $28 \mathrm{~min}$ to $1 \mathrm{~h}$ and $50 \mathrm{~min}$, with the average length being 40-50 min. The interviews were fully transcribed verbatim, with two exceptions; two interviewees gradually turned to describing their private life (for example, relationship with their family members) as the interview progressed, and since this was irrelevant to the study, these parts were deleted. However, sections relevant to the topic were retained.

The audio recordings of the interviews were listened to repeatedly, and then, the Chinese transcripts were imported into MaxQDA for further analysis. They were analysed thematically in relation to the two research questions. Themes and codes were refined several times until a "satisfactory thematic map" (Braun and Clarke 2006, p. 22) of the data had been generated.

\section{Results}

\section{Core quantitative study: statistical results}

Three questions in the SB and ISB probed satisfaction with different friendship groupings. According to our results, the majority of all groups of respondents indicated that they were generally

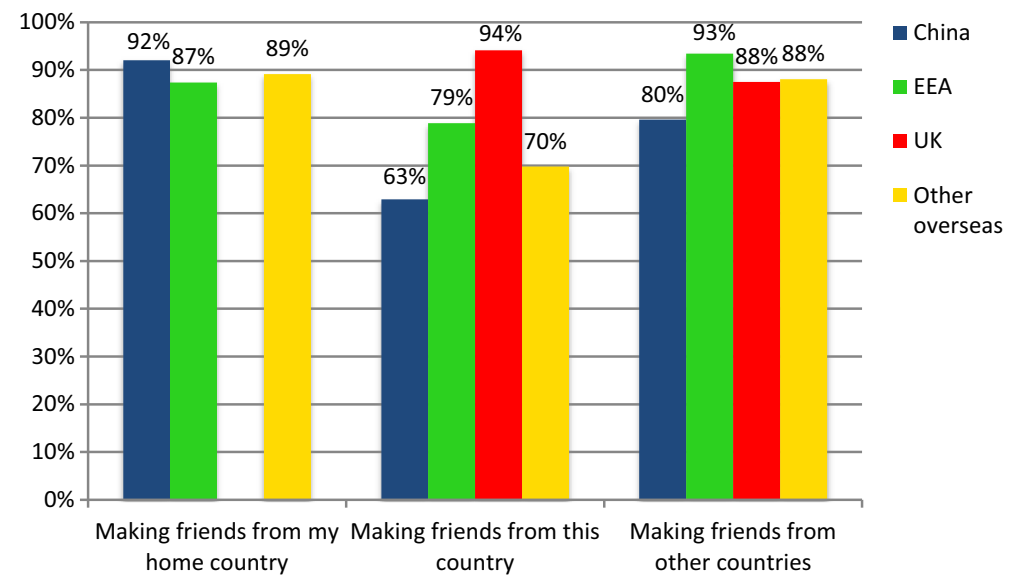

Fig. 1 The proportion of students $(n=2031)$ who are satisfied with making friends from different places 


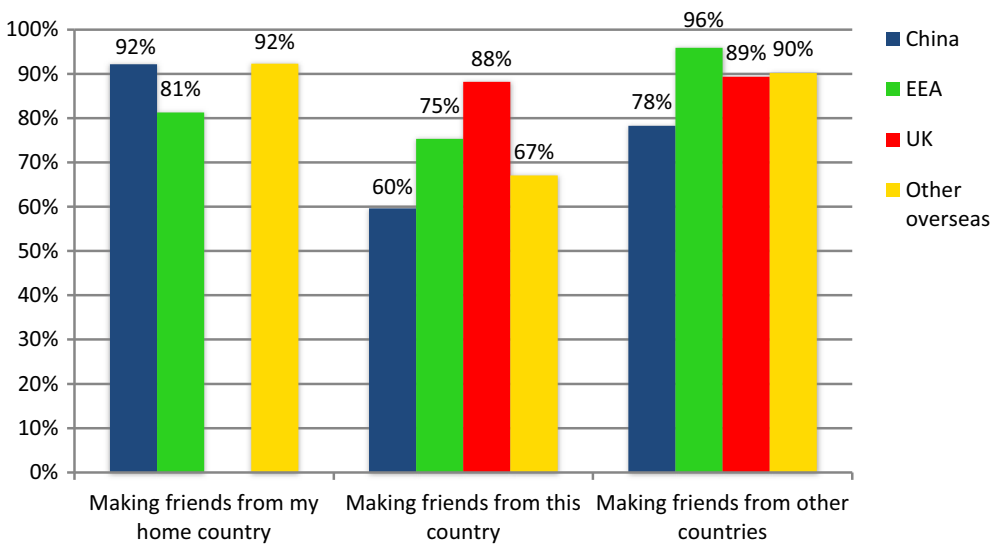

Fig. 2 The proportion of PGT students $(n=526)$ who are satisfied with making friends from different places

satisfied with their friendship experiences, in that more than $50 \%$ expressed satisfaction. Figure 1 shows the results for the full sample, and Fig. 2 shows them for the PGT sample, which had a particularly high proportion of Chinese respondents (see Table 1). Nevertheless, as can be seen from the percentages in both figures, whilst a very high percentage of Chinese students $(92 \%$ for both the full sample and PGTs only) were satisfied or very satisfied with their opportunities to make friends with their compatriots, far fewer (63\% for the full sample and $60 \%$ for PGTS) were satisfied with their opportunities to make friends with British students. Their satisfaction scores for friendships with compatriots, British and other internationals were more extreme than for any of the other regional groups. Whilst no significant difference was found for the question relating to making friends from their home country neither for the entire sample $(\mathrm{H}(2)=0.610, p=0.737)$ nor for the PGT sample $(\mathrm{H}(2)=0.22119, p=0.895)$, differences were more pronounced and mostly significant

Table 2 Wilcoxon rank sum test for pairwise comparisons related to satisfaction with making friends from different countries

\begin{tabular}{|c|c|c|c|c|c|c|c|}
\hline \multirow[t]{2}{*}{ Question } & \multirow{2}{*}{$\begin{array}{l}\text { Sample } \\
\text { pairing }\end{array}$} & \multicolumn{3}{|c|}{ Entire sample } & \multicolumn{3}{|l|}{ PGT } \\
\hline & & $\begin{array}{l}\text { Wilcoxon } \\
W\end{array}$ & $\begin{array}{l}p \\
\text { value }\end{array}$ & $r$ & $\begin{array}{l}\text { Wilcoxon } \\
W\end{array}$ & $\begin{array}{l}p \\
\text { value }\end{array}$ & $r$ \\
\hline \multirow[t]{6}{*}{ Making friends from this country } & China-EEA & 13,278 & $<0.001$ & -0.288 & $3,048.5$ & $<0.001$ & -0.243 \\
\hline & China-UK & 37,413 & $<0.001$ & -0.574 & 3,764 & $<0.001$ & -0.505 \\
\hline & China-other & 25,364 & $<0.001$ & -0.148 & 8,576 & 0.074 & -0.130 \\
\hline & EEA-UK & 113,250 & $<0.001$ & -0.234 & 3,656 & 0.007 & -0.197 \\
\hline & EEA-other & 60,285 & $<0.001$ & -0.191 & $7,168.5$ & 0.038 & -0.151 \\
\hline & UK-other & 134,170 & $<0.001$ & -0.568 & $6,804.5$ & $<0.001$ & -0.429 \\
\hline \multirow{6}{*}{$\begin{array}{l}\text { Making friends from other } \\
\text { countries }\end{array}$} & China-EEA & 12,788 & $<0.001$ & -0.326 & $2,733.5$ & $<0.001$ & -0.328 \\
\hline & China-UK & 63,810 & $<0.001$ & -0.212 & $5,287.5$ & $<0.001$ & -0.265 \\
\hline & China-other & 24,784 & $<0.001$ & -0.189 & 7,965 & 0.001 & -0.237 \\
\hline & EEA-UK & 157,350 & $<0.001$ & -0.220 & 4,869 & 0.224 & -0.089 \\
\hline & EEA-other & 61,186 & $<0.001$ & -0.203 & 7,326 & 0.025 & -0.164 \\
\hline & UK-other & 207,880 & 0.807 & -0.012 & $9,921.5$ & 0.326 & -0.072 \\
\hline
\end{tabular}

Pairs in italic show the effect sizes of $r>0.3$ 


\section{I find it difficult to socialise with people who are from different countries}

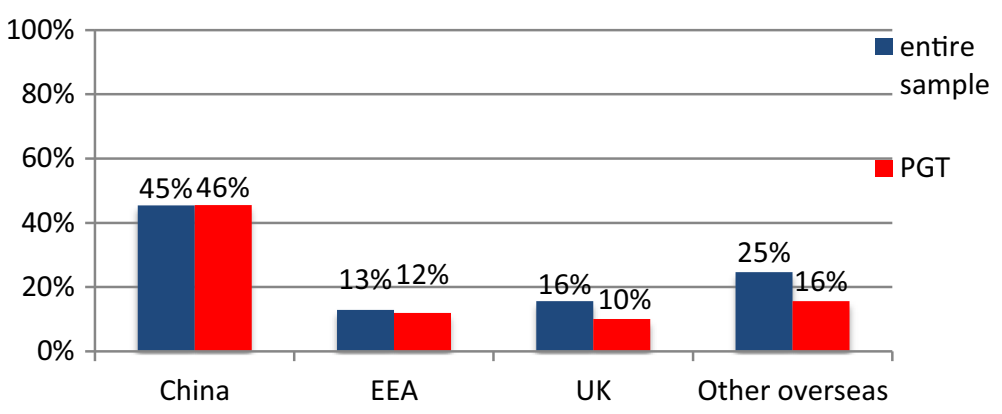

Fig. 3 The proportion of students ( $n=2031$ for entire sample, $n=526$ for PGTs) who agreed with the following statement: "I find it difficult to socialise with people who are from different countries"

for the other two questions, "making friends from this country" (entire sample $\mathrm{H}(3)=217.27$, $p<0.001$; PGT sample $\mathrm{H}(3)=56.222, p<0.001$ ) and "making friends from other countries" (entire sample $\mathrm{H}(3)=46.26, p<0.001$; PGT sample $\mathrm{H}(3)=24.462, p<0.001)$.

A follow-up pairwise comparison (see Table 2) confirmed that differences between Chinese and other students on campus are more pronounced than for any other group pairings.

Another question in the survey probed respondents' perceived difficulty in socialising with people from different countries. As can be seen from Fig. 3, although the proportion perceiving it to be difficult was less than $50 \%$ for all regional clusters, Chinese students found it noticeably more difficult than others. Forty-five percent of PRC students reported having difficulty in interacting socially with people from different countries, compared with $13 \%$ of students from the European economic area (excluding UK), $14 \%$ of UK students and $24 \%$ of other non-PRC overseas students. These figures were similar, or even slightly more pronounced, for PGTs. The differences were statistically significant $(\mathrm{H}(3)=117.68, p<0.001$ for the whole sample; $\mathrm{H}(3)=85.457, p<0.001)$.

Table 3 provides a follow-up analysis, showing pairwise comparisons. As can be seen, only differences between China and other countries show a relevant difference, with effect sizes $(r)$ larger than 0.3 , indicating medium to large effect size. However, EEA, UK and other overseas

Table 3 Wilcoxon rank sum test for pairwise comparisons, "I find it difficult to socialise with people who are from different countries"

\begin{tabular}{|c|c|c|c|c|c|c|}
\hline \multirow[t]{2}{*}{ Sample pairing } & \multicolumn{3}{|l|}{ Entire sample } & \multicolumn{3}{|l|}{ PGT } \\
\hline & Wilcoxon $W$ & $\begin{array}{l}p \\
\text { value }\end{array}$ & $r$ & Wilcoxon $W$ & $\begin{array}{l}p \\
\text { value }\end{array}$ & $r$ \\
\hline China-EEA & 28,229 & $<0.001$ & -0.483 & $6,722.5$ & $<0.001$ & -0.536 \\
\hline China-UK & 105,590 & $<0.001$ & -0.465 & 11,155 & $<0.001$ & -0.570 \\
\hline China-other & 37,660 & $<0.001$ & -0.318 & 13,386 & $<0.001$ & -0.490 \\
\hline EEA-UK & 109,830 & $<0.001$ & -0.216 & $4,320.5$ & 0.159 & -0.103 \\
\hline EEA-other & 38,442 & $<0.001$ & -0.272 & 4,863 & 0.003 & -0.216 \\
\hline UK-other & 220,500 & 0.004 & -0.146 & 12,000 & 0.051 & -0.143 \\
\hline
\end{tabular}

Pairs in italic show the effect sizes of $r>0.3$ 
countries show almost only small, largely negligible effect sizes and therefore not particularly large differences between these groups of students.

These results indicate that the Chinese student integration issue reported in the UKCOSA (2004) study, whilst improved, is still prevalent over 10 years later. Moreover, the findings demonstrate not only that around $40 \%$ of Chinese students are dissatisfied with the situation but also that they find it positively more difficult to socialise with people from other countries than students of other nationalities do. This raises a fundamental question, why is social integration more difficult for Chinese students than for students of other nationalities? Some preliminary indications are offered by the open comments in the survey, as the next sub-section reports.

\section{Core quantitative study: open comments}

A number of respondents made open comments specifically on Chinese students, and these were selected for analysis. They were coded into the six categories shown in Table 4.

Three people made positive or neutral comments (that they had a Chinese friend or that the wide range of nationalities on campus was impressive), but 25 out of the 28 comments were critical. As can be seen from the table, the Chinese students themselves commented that there were large numbers of Chinese and that this limited their opportunities. The following comments illustrate this:

C1. Too many Chinese student in the course; $95 \%$ or plus are from China. (PRC, male PGT)

$\mathrm{C} 2$. Lecture size is too big, more than 150 students in my major; however, $90 \%$ are Chinese! I felt I was in Chinese classroom when I first attended the lectures!!! (PRC, female PGT)

C3. No opportunity because all my classmates and roommates are Chinese. (PRC, female $P G T)$

The respondents of other nationalities commented negatively on the Chinese students, saying that they did not want to integrate, rarely socialised with non-Chinese, were uncooperative, participated too little in discussions and that they spoke Chinese together too much. Some of the comments were quite strong.

C4. Many foreign students, particularly Chinese, don't want to integrate. (UK, male UG)

Table 4 Thematic comments referring to Chinese people/nationality made by students of different nationalities

\begin{tabular}{lrrrrr}
\hline Nationality theme & UK & China & EEA & Other $\begin{array}{l}\text { Total number of comments made about } \\
\text { Chinese students }\end{array}$ \\
& 2 & 0 & 0 & 0 & 2 \\
Have Chinese friend(s) & 1 & 0 & 0 & 0 & 1 \\
$\begin{array}{l}\text { Impressive range of nationalities on } \\
\quad \text { campus }\end{array}$ & 1 & 5 & 0 & 5 & 11 \\
$\quad$ Large numbers of Chinese/too & 5 & 0 & 0 & 2 & 7 \\
$\quad 3$ & 0 & 0 & 1 & 4 \\
Insular/uncooperative & 2 & 0 & 0 & 1 & 3 \\
Speak in Chinese & 14 & 5 & 0 & 9 & 28 \\
Participate little & & & & & \\
Total & & &
\end{tabular}


C5. Without meaning to sound racist, the Chinese people in our flat never socialise with any of us. They don't even say hi when we do... (UK, female UG)

C6. My experience of halls this year has tarred my opinion of Chinese students who in my experience act in an insular fashion. I have not had the same experience with international students from other countries. (UK, male PGT)

C7. Many students from China are simply uncooperative. Not a nice opinion to hold but a common one. (UK, male UG)

C8. Half the people don't say anything! Especially the Chinese! (No offence intended) (Malawi, male PGT)

C9. I am the only British national living in my flat; socialising with the Chinese students is a lost cause as they all speak Chinese at all times. (UK, male PGT)

\section{Extension qualitative study}

Figure 4 below shows the friendship patterns of the interviewees. As can be seen, a range of patterns are represented, indicating that a variety of viewpoints and experiences are likely to be expressed.

The coding of the interview data on the barriers to social integration yielded five main issues. These are shown in Fig. 5, which is a screenshot from the MaxQDA project file. The columns containing the small squares represent the 25 interviewees ${ }^{4}$, the size of square indicates the frequency of an interviewee mentioning an issue and the figure in the far righthand column indicates the total number of codings per main code and sub-code (for this summation figure, hits per interviewee were counted only once per code and sub-code). We report on these five main issues in turn below.

\section{Individual factors}

Individual factors were mentioned most frequently by interviewees as the reason for lack of social integration. Personal motivation (or rather lack of motivation) for social integration was identified as a key issue. For example, one student commented as follows:

Some students do not come here for the interaction; instead, they just want to study and get the diploma; however, some students might be willing to develop themselves in this field. So you have to notice that individual differences contributed to this. (A, female PGT)

Several interviewees maintained that it was unnecessary for Chinese students to make friends with foreigners because they had their own groups and did not need to because "they can make friends on $\mathrm{WeChat}^{5}$ and the Internet, and they could lead a happy life without any British friends". (Y, male PGR)

Another frequent theme was the importance of personal qualities, with some people arguing that those who are open-minded and outgoing usually integrate better than those who are introverted.

\footnotetext{
${ }^{4}$ Two students were interviewed together, and this shows as single entry in MaxQDA, hence the 24 columns.

${ }^{5}$ A social network very popular among Chinese.
} 
Fig. 4 Reported friendship patterns of the interviewees

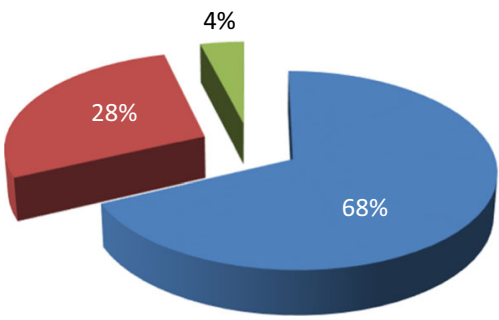

Mainly/solely Chinese

Approx. half Chinese, half non-Chinese

Mainly international students

I think it is because of my characteristics - I am a bit shy... There is a girl in my class who is very open and mingles very well with foreigners. I think it depends on individual characteristics. (M, female PGT)

Some referred to the degree of willingness to overcome difficulties.

Sometimes I am lazy. It is too tiring, not as relaxing as with Chinese friends. (R, female PGT)

You have to allow some time to get to know each other. Many people were intimidated by this and failed to cross the threshold. I have crossed it, but only slightly. (L, male PGT)

Others mentioned face sensitivity, for example, "You have to be polite all the time and you cannot lose face for Chinese people... this is really tiring" (Z, male PGT), and some used the Chinese word 随缘 “suiyuan", which means "let fate take its course", to describe their passive attitude towards socialising with foreigners. A few admitted to being prejudiced against national groups such as Indians (Z, male PGT) and "British... because of their sense of superiority". (G, male PGT)

\section{Cultural distance}

Cultural distance was clearly a major issue for the respondents. Their comments related to two different sides of the same coin, cultural differences with non-Chinese and sense of cultural affinity with PRC students. Regarding the former, differences mentioned included different habits/preferences, different background knowledge, different conceptions of friendship and different ways of interacting and coping with unfamiliar taboos, as the following sample quotations illustrate:

I seriously do not like drinking or clubbing. I can force myself to speak English and make foreign friends, but I cannot go to the clubs. It is disgraced. This is a serious cultural conflict. (I, female PGT)
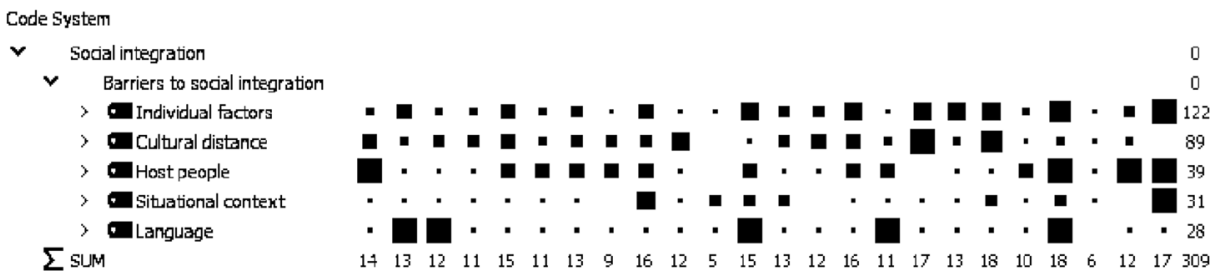

Fig. 5 Screenshot from MaxQDA of the codings on main barriers to social integration 
I really do not know what to talk with them. I only focus on news in China, but they talk about things happening in Britain. (N, female PGT)

The friendship with Chinese and other Asians does not rely on meeting each other every day... But if you do not see a foreign friend for a month, you will become really distant next time you meet. (Q, female PGT)

Europeans lay great emphasis on their privacy and opinions. They are very direct in expressing themselves... Chinese tend to be more obedient. (S, female PGT)

Whilst many believed that these differences contributed to their reluctance to build friendships with "foreigners", a few felt these factors were not a barrier but rather offered an opportunity to "learn about other people's thoughts" (S, female PGT), and a few claimed to have embraced habits such as drinking and clubbing.

In terms of cultural affinity, issues mentioned included a sense of emotional bond to Chinese or even other Asians, mutual care and problem solving, prevention of loneliness and common world views. The following comments illustrate these points:

The emotional bond becomes stronger in this foreign land. (G, male PGT)

Sometimes the closeness could even extend to other Asians without any reason. $(\mathrm{H}$, female PGT)

When your discussions proceed to in-depth issues like ideologies, the differences in the way of thinking, the view of life, the world view and value system would emerge. (W, male PGT)

Chinese students are disadvantaged groups here. We stay together so that we can take care of each other... There was an earthquake in my hometown... All Chinese students learned about it. They proposed a toast to me and asked if my family was OK. (G, male PGT)

We can share information about visa. People from many other countries do not need this, but we do. (R, female PGT)

Chinese students do not want to be lonely here, so they need friends. That is the prerequisite and the reason they stay with each other. (E, female PGT)

A few of the students, however, mentioned that spending too much time with other Chinese people was boring.

\section{Host people}

According to many of the respondents, whether the other party shows an interest in making contact is also important, arguing that the attitudes of non-Chinese students were crucial. Some mentioned that although they had made friends with foreign students who have "nice characteristics" (Z, male PGT), they "cannot do anything if the other party is close-minded" (B, male PGT). Others talked about the importance of foreigners being interested in China or Chinese culture.

Some said that "foreign students were very polite, but they did not show any intention of talking much to you... or making friends with you". (A, female PGT). On the other hand, yet others argued the opposite,

Everyone is open to you if you want to integrate, at least from my experience... Undoubtedly, we need to integrate into the British culture, the local mainstream culture, instead of the other way round... Chinese students should take the initiative. Local students have a lot of friends, and it does not make much difference for them to have you as a friend or not. (Y, male PGR) 


\section{Situational context}

Many interviewees mentioned the impact of the situational context. A key factor was the number of Chinese and the limited number of British students on some courses. Other issues mentioned included the influence of friends, the campus location, the (lack of) opportunity for internships or part-time jobs and the responsibility of the university/department to promote integration. See, for example, following sample comments:

The presence of too many Chinese hampers me in getting in touch with foreigners. (I, female PGT)

No British would study for a master's degree. It is the same in any university. $90 \%$ of the postgraduate students are from other countries. (E, female PGT)

This is a village... I was living in a city as an undergraduate student, which gave me a lot of opportunities to meet foreigners in the city centre. (P, female PGT)

I want to try some internship as you can integrate better when you are in a company. $(\mathrm{H}$, female PGT)

I think the intervention from the university is quite important. Some students are really happy to have the chance to meet local people - such meetings are organised by my department. If not, they might just stay in their own rooms. (R, female PGT)

\section{Language}

Finally, all but one of the interviewees raised the issue of language.

Language is very important. We are all good at expressing our ideas in our native language... Maybe Chinese students can only talk about plain stuff with foreigners. (W, male PGT)

However, they held different viewpoints on the impact of language on integration. Some regarded it as a decisive factor, some believed it to be primarily a confidence issue, whilst others maintained that language should not be used as an excuse.

It is difficult to make friends with foreigners... first and foremost, language. It is the crucial factor. (D, female PGT)

If they are able to come and study in this university, they are able to express themselves. It has nothing to do with language fluency, it's more of a confidence issue. They do not believe that they are good enough, but actually they might speak better English than many Europeans. (Y, male PGR)

Language is a tool, not a big problem... the exchange of ideas is the main purpose... I often hang out with foreign students, but it does not mean I speak good English. They can understand you as long as you can express yourself, even with poor English. (O, female PGT)

\section{Discussion}

The survey findings from our core quantitative study provided us with a clear answer to our first research question, how satisfied are Chinese students with their social integration into the university community? Whilst a good proportion of them are satisfied with their non-Chinese 
friendships, their level of satisfaction is significantly lower than that of other students. They also reported finding it significantly more difficult to socialise with people from different countries than other nationalities did. This led us to our second research question, what barriers the Chinese students themselves perceive in becoming more socially integrated into the university community?

The limited findings from the open comments indicate that one barrier could be the large numbers of PRC students in the BHEI student population. Given the large pool of Chinese students at the BHEI, the PRC students could experience greater temptation (as well as opportunity) than other overseas students to take the easy route and simply make friends with their compatriots.

As Kim (2001) and Berry (2006) point out, high social integration requires others to be positive, and in the case of universities, this involves the whole student community. As the open comments from the survey indicate, at least a portion of the British and other international student groups were critical of the PRC students' behaviour and attitudes, so this may have discouraged them and thereby acted as another barrier, leading to their perception of greater difficulty in integrating socially.

However, these are only two possible reasons for Chinese students' perceived barriers to integration, based on limited open comments. Our extension qualitative study allowed us to explore this in greater depth. Five main barriers were identified and two of these relate to the factors identified in cross-cultural psychological research as having a significant impact on adaptation, cultural distance and host-guest interaction. They were perceived as being a particular challenge, whilst individual factors, and especially people's personal motivation, also had a crucial influence. Although some students were keen to build friendships with people from different backgrounds, others expressed no interest in this, maintaining that their primary goal was academic. Yet, others appeared interested in theory but found it hard to resist the attraction, comfort and ease of socialising with their compatriots, since they were surrounded by so many. This was exacerbated if students of other nationalities, and especially UK students, showed little personal interest in them or in China.

Taking our sequential mixed-method study as a whole, then, our key findings can be summarised as follows:

RQ1: PRC students are less satisfied with their opportunities for friendships with British students and with other international students than students of other nationalities. Some also feel that they have greater difficulty than other students in making friends with non-Chinese students.

RQ2: PRC students perceive a range of barriers to social integration; some of which are contextual (e.g. the large number of PRC students on the campus and limited opportunities to meet people from the local community), but many of which stem from personal preferences. Factors such as personality, preference for an "easy option", emotional satisfaction from mixing with people with a similar background and language factors all interact to mitigate against high levels of social integration.

This brings us back to the question we considered above in the literature review, why is social integration important? The cross-cultural psychology literature indicates that it is beneficial for adaptation and social learning reasons. One might argue that this in fact is less applicable to PRC students because their compatriots not only often play a major role in meeting their psychological needs but also in meeting their social ones. As Chen and Ross 
(2015, p. 174) argue, Chinese student communities "can protect Chinese undergraduate students from campus stereotypes and provide social, academic and spiritual support." Ross and Chen (2015, p. 21) further explain this perspective as follows:

The ability to associate with Chinese "like oneself" is directly related to the number of Chinese students on campus. To be sustained, mono-ethnic communities require a critical mass of similar bodies. The larger these communities, the greater pull they have for international students. Language and cultural nuances are factors here. If there are enough Chinese students to form a circle of friends, students have less incentive to try to break into an American peer group that is continually created, for example, through references to popular culture that remain linguistically and culturally distant from uninitiated international students [...]. In contrast, information networks, Chinese social media and student organisations provide the Chinese student community with space for social capital formation and protect Chinese undergraduate students from campus stereotypes.

One might conclude, then, that increasing the social integration of PRC students is unlikely to be successful and, in any case, unnecessary, as their social and adaptation needs can be met by their compatriot community. However, we would argue that this would be too hasty a conclusion. Chen and Ross (2015) also point out that not all PRC students are happy with the situation, and our findings on RQ1 support this viewpoint. Our respondents were significantly more dissatisfied with their non-Chinese friendships than students of other nationalities were. Forty percent of Chinese postgraduate taught students were not satisfied and $37 \%$ of Chinese students overall. This is a substantial proportion, and it would be unwise for universities to ignore the issue.

There are also other important reasons. Crawford and Wang (2015) report that the academic performance levels of Chinese and UK undergraduate students display an increasing gap over the 3-year degree period, with the Chinese students falling significantly behind. They recommend researching teaching and learning factors to understand better why this is happening. However, Glass and Westmont's (2014) study suggests that we need to take a holistic approach to education, which includes socialisation and identity factors as well as teaching and learning, if we are to gain a deeper understanding of the factors that affect academic success. Moreover, a recent study of the employability (in China) of UK-educated Chinese students (Young 2016) found that Chinese alumni strongly recommend PRC students to move outside Chinese circles so that they can broaden their experiences and develop the qualities that Chinese employers are looking for.

The studies indicate, then, that universities should address the issue of integration for a range of reasons, including student satisfaction, future employability and possibly academic success. Given the financial benefits that PRC students bring to universities, combined with market demand from China for places, it is unlikely that universities will want to reduce the numbers of Chinese students they recruit. So how can they address the situation? There have been many initiatives on the social front (for example from a range of universities, see Spencer-Oatey et al. 2014) but little or no empirical research to explore their effectiveness. Even less has been done to assess and/or improve academic integration - a complementary aspect that could have spin-off benefits. So in this respect, the recent new diagnostic tool launched by i-Graduate, the Global Education Profiler, which probes both social and academic integration as well as levels of global skills and support, offers an excellent opportunity to conduct research that monitors this area and evaluates the impact (or otherwise) of different initiatives. 


\section{Limitations and concluding comments}

The studies reported in this article were carried out at a single university in the UK, with only PGT students and with only a limited number of interviewees. The findings should therefore not be assumed to apply exactly to other HE institutions or even uniformly across the same institution. There are likely to be noticeable contextual differences, such as the proportion of Chinese students at a particular university and/or on different degree programmes, as well as the impact of factors like level of study, extracurricular activities available, integration initiatives and importance attached to the development of intercultural skills. Moreover, surveys can only provide broad brush insights whilst interviews are naturally limited in number, with potential biases in recruitment of participants.

Nevertheless, the findings are likely to be indicative of the situation in many universities, in Britain and beyond, in view of the large numbers of PRC students studying at universities worldwide. What is needed now is more research into (a) students' attitudes towards and experiences of social and academic integration at different institutions and in different contexts and (b) more effective monitoring of the level of impact of any initiatives. We hope that this study will provide an impetus for further research on these issues.

Acknowledgements The authors would like to thank two anonymous reviewers for their feedback on an earlier version of this article.

Open Access This article is distributed under the terms of the Creative Commons Attribution 4.0 International License (http://creativecommons.org/licenses/by/4.0/), which permits unrestricted use, distribution, and reproduction in any medium, provided you give appropriate credit to the original author(s) and the source, provide a link to the Creative Commons license, and indicate if changes were made.

\section{References}

Belkin, D., \& Jordan, M. (2016). Heavy recruitment of Chinese students sows discord on US campuses. Wall Street Journal. http:/www.wsj.com/articles/heavy-recruitment-of-chinese-students-sows-discord-on-u-scampuses-1458224413.

Berry, J. W. (2006). Contexts of acculturation. In D. L. Sam \& J. W. Berry (Eds.), The Cambridge handbook of acculturation psychology (pp. 27-42). Cambridge: CUP.

Boski, P. (2008). Five meanings of integration in acculturation research. International Journal of Intercultural Relations, 32, 142-153.

Braun, V., \& Clarke, V. (2006). Using thematic analysis in psychology. Qual Res Psychol, 3(2), 77101.

British Council (2014). Integration of international students-a UK perspective. London: British Council Available at https://www.britishcouncil.org/education/ihe/knowledge-centre/student-mobility/reportintegration-international-students.

Chen, Y., \& Ross, H. (2015). "Creating a home away from home": Chinese undergraduate student enclaves in US higher education. Journal of Current Chinese Affairs, 44(3), 155-181.

Crawford, I., \& Wang, Z. (2015). The impact of individual factors on the academic attainment of Chinese and UK students in higher education. Stud High Educ, 40(5), 902-920.

Davis, R. E., Couper, M. P., Janz, N. K., Caldwell, C. H., \& Resnicow, K. (2010). Interviewer effects in public health surveys. Health Educ Res, 25(1), 14-26.

Denscombe, M. (2007). The good research guide for small-scale social research projects. 3rd edition. Milton Keynes: Open University.

Furnham, A., \& Bochner, S. (1982). Social difficulty in a foreign culture: an empirical analysis of culture shock. In S. Bochner (Ed.), Cultures in contact: studies in cross-cultural interaction (pp. 161-198). Oxford: Pergamon. 
Glass, C. R., \& Westmont, C. M. (2014). Comparative effects of belongingness on the academic success and cross-cultural interactions of domestic and international students. International Journal of Intercultural Relations, 38, 106-119.

Hodkinson, C. S., \& Proropat, A. E. (2014). Chinese students' participation: the effect of cultural factors. Education + Training, 56(5), 430-446.

Hsieh, H.-F., \& Shannon, S. E. (2005). Three approaches to qualitative content analysis. Qual Health Res, 15(9), 1277-1288.

Jin, L., \& Cortazzi, M. (2006). Changing practices in Chinese cultures of learning. Language, Culture and Curriculum, 19(1), 5-20.

Jin, L., \& Cortazzi, M. (Eds.) (2011). Researching Chinese learners. Skills, perceptions and intercultural adaptations. Basingstoke: Palgrave Macmillan.

Kim, Y. Y. (2001). Becoming intercultural. An integrative theory of communication and cross-cultural adaptation. Thousand Oaks: Sage.

Liu, J. (2002). Negotiating silence in American classrooms: three Chinese cases. Language and Intercultural Communication, 2(1), 37-54.

Morgan, D. L. (2014). Integrating qualitative and quantitative methods. A pragmatic approach. Los Angeles: Sage.

Peacock, N., \& Harrison, N. (2009). "It's so much easier to go with what's easy": "mindfulness" and the discourse between home and international students in the United Kingdom. J Stud Int Educ, 13(4), 487-508.

Ross, H., \& Chen, Y. (2015). Engaging Chinese international undergraduate students in the American university. Learning and Teaching, 8(3), 13-36.

Sovic, S. (2009). Hi-bye friends and the herd instinct: international and home students in the creative arts. High Educ, 58(6), 747-761.

Spencer-Oatey, H., \& Dauber, D. (2016). The gains and pains of mixed national group work at university. Journal of Multilingual and Multicultural Development. doi:10.1080/01434632.01432015.01134549.

Spencer-Oatey, H., \& Xiong, Z. (2006). Chinese students' psychological and sociocultural adjustments to Britain: an empirical study. Language, Culture and Curriculum, 19(1), 37-53.

Spencer-Oatey, H., Dauber, D., \& Williams, S. (2014). Promoting integration on campus: principles, practice and issues for further exploration. UCKISA with the University of Warwick. http://www2.warwick.ac. uk/fac/cross fac/globalpeople/integration/. Accessed 5 March 2016.

UKCOSA (2004). Broadening our horizons. International students in UK universities and colleges. Available at http://institutions.ukcisa.org.uk/Info-for-universities-colleges-schools/Publications-research/resources/90 /Broadening-Our-Horizons-Survey-2004, London.

UNESCO (2016). Institute for Statistics. http://www.uis.unesco.org/EDUCATION/Pages/international-studentflow-viz.aspx. Accessed 4 March 2016.

Ward, C., \& Kennedy, A. (1993a). Psychological and sociocultural adjustment during cross-cultural transitions: a comparison of secondary students at home and abroad. Int J Psychol, 28, 129-147.

Ward, C., \& Kennedy, A. (1993b). Where's the 'culture' in cross-cultural transition? Comparative studies of sojourner adjustment. J Cross-Cult Psychol, 24(2), 221-249.

Young, L. (2016). Enhancing the employment success of UK-educated Chinese students. University of Warwick and AGCAS joint project report, presented at The Shard, London, 18 May 2016: http://www.agcas.org. uk/events/1276-Chinese-Employability-Project-Warwick-AGCAS-The-Shard-London. 